\title{
Coronary microvascular function in athletes with abnormal exercise test results
}

\author{
D. A. J. P. van de Sande (D) - P. C. Barneveld · J. Hoogsteen · P. A. Doevendans · H. M. C. Kemps
}

Published online: 25 October 2019

(C) The Author(s) 2019

\begin{abstract}
Aims In asymptomatic athletes, abnormal exercise test (ET) results have a poor positive predictive value. It is unknown whether abnormal ET results in the absence of obstructive coronary artery disease (CAD) are related to coronary microvascular dysfunction. It is also unknown whether they should be considered false-positive ET results or a consequence of physiological adaptation to sport. In our study, we evaluated whether athletes with abnormal ET results and documented myocardial ischaemia in the absence of obstructive CAD have an attenuated microvascular function and whether coronary microvascular dysfunction is related to endothelial dysfunction.

Methods and results Nine athletes with concordant abnormal ET and myocardial perfusion scintigraphy (MPS) results without obstructive CAD were compared with age- and gender-matched individuals with a low-to-intermediate a priori risk of CAD. Coronary flow reserve was assessed by Rubidium82 positron emission tomography (PET) imaging. Endothelin-1 concentrations were measured to evaluate endothelial function. Coronary flow reserve was
\end{abstract}

\footnotetext{
D. A. J. P. van de Sande $(\varangle) \cdot$ J. Hoogsteen · H. M. C. Kemps Department of Cardiology, Máxima Medical Center, Veldhoven, The Netherlands

d.vandesande@mmc.nl

P. C. Barneveld

Department of Nuclear Medicine, Jeroen Bosch Hospital, 's-Hertogenbosch, The Netherlands

\section{P. A. Doevendans}

Department of Cardiology, University Medical Center Utrecht, Utrecht, The Netherlands

Centraal Militair Hospitaal (CMH), Utrecht, The Netherlands

Heart and Lungs, Netherlands Heart Institute (NHI), Utrecht, The Netherlands
}

significantly lower in athletes $(3.3 \pm 0.8$ versus $4.2 \pm 0.6$, $p=0.014$ respectively). Endothelin-1 levels were significantly higher in athletes $(1.3 \pm 0.2 \mathrm{pg} / \mathrm{ml}$ versus $1.0 \pm 0.2 \mathrm{pg} / \mathrm{ml}, p=0.012$ respectively). There was no correlation between endothelin-1 concentrations and mean global coronary flow reserve $(r=0.12)$.

Conclusion Athletes with abnormal ET and MPS outcomes indicative for myocardial ischaemia and no obstructive $\mathrm{CAD}$ have a lower coronary flow reserve compared with non-athletes with low-to-intermediate a priori risk of $\mathrm{CAD}$, suggesting an attenuated coronary microvascular function. Higher endothelin-1 concentrations in athletes suggest that endothelialdependent dysfunction is an important determinant of the attenuated microvascular function.

Keywords Athletes - Coronary microvascular function - Coronary flow reserve - Exercise testing

\section{What's new}

- Athletes with abnormal exercise testing and myocardial perfusion scintigraphy outcomes indicative for myocardial ischaemia in the absence of obstructive coronary artery disease have a lower coronary flow reserve compared with non-athletes with low-to-intermediate a priori risk of coronary artery disease.

- These findings suggest an attenuated coronary microvascular function.

- Higher endothelin-1 concentrations in athletes suggest that endothelial-dependent dysfunction is an important determinant of the attenuated microvascular function. 


\section{Introduction}

The use of pre-participation screening in athletes to detect underlying cardiac diseases is recommended by the American Heart Association and the European Association of Cardiovascular Prevention and Rehabilitation $[1,2]$. According to these guidelines, the use of exercise testing (ET) is restricted to individuals who show abnormalities suggestive for cardiac disease during primary screening or individuals with one or more traditional risk factors. However, in daily practice, many sporting events require athletes from every athletic level and age to perform an exercise test [3].

A problem associated with ET in asymptomatic athletes is its poor positive predictive value. In fact, a recent review demonstrated that obstructive coronary artery disease (CAD) was absent in up to $90 \%$ of the athletes with abnormal ET results [4]. Even when combined with myocardial perfusion scintigraphy (MPS), obstructive CAD was still absent in $80 \%$ of the athletes with concordant abnormal ET and MPS results [5].

Currently, it remains unknown whether concordant abnormal ET and MPS results in athletes should be considered false-positive test results, a consequence of physiological adaptation to sport, or a consequence of coronary microvascular dysfunction. Previous studies demonstrated an increased risk of major adverse cardiac events (MACE) in both non-athletic patients and athletes with abnormal ET and MPS results without obstructive CAD [5, 6], suggesting a pathophysiological basis of concordant abnormal test results. Moreover, results of animal studies suggested that coronary microvascular dysfunction may indeed play a role due to an inadequate increase in myocardial capillary density in response to development of training-induced myocardial remodelling/hypertrophy, remodelling of the intramural coronary arteries, autonomic imbalance or endothelial dysfunction $[7,8]$. However, to date, no studies are available that address the coronary microvascular function in athletes with abnormal ET results. Therefore, the aim of the present study was to evaluate whether athletes with concordant abnormal ET and MPS results in the absence of obstructive CAD have an impaired coronary microvascular function as assessed by coronary flow reserve (CFR) and, furthermore, to evaluate whether coronary microvascular function was associated with endothelial dysfunction.

\section{Methods}

\section{Study design and population}

This study was designed as a single-centre prospective observational case-control study among asymptomatic recreational and competitive athletes who underwent pre-participation screening at the Department of Sports Medicine of the Máxima Medical
Center and visited the department of Cardiology of the Máxima Medical Center. Athletes were defined as individuals who practise sports for at least $2.5 \mathrm{~h}$ a week for at least 30 weeks per year [9]. Asymptomatic athletes with an abnormal ET and abnormal MPS indicating myocardial ischaemia without obstructive CAD on coronary computed tomography angiography (CCTA) or coronary angiography within the last five years were selected from a previous study which enrolled 753 athletes. A total of 102 athletes (13.5\%) showed abnormal ET results of which 51 underwent MPS. In the present study, the 9 athletes with abnormal ET and MPS results without obstructive CAD were included and underwent Rubidium-82 $\left({ }^{82} \mathrm{Rb}\right)$ positron emission tomography (PET) imaging and CCTA in the Jeroen Bosch Hospital located in 's-Hertogenbosch, the Netherlands. Prior to the ${ }^{82} \mathrm{Rb}$ PET imaging and CCTA, the athletes underwent a direct venipuncture for the collection of blood samples (kidney function, lipid profile, endothelin-1, glucose levels, C-reactive protein and leucocyte count). After completion of the ${ }^{82} \mathrm{Rb}$-PET imaging, CCTA and venipuncture, all data of the athletes were interpreted and analysed. When data of ${ }^{82} \mathrm{Rb}$-PET imaging and CCTA were suitable for proper analysis, the athletes were matched according to gender (1:1) and age (years \pm 2 years) with nonathletic individuals with a low-to-intermediate a priori risk of CAD according to the European Society of Cardiology (ESC) SCORE risk [10] and no obstructive CAD who already underwent ${ }^{82} \mathrm{Rb}$-PET imaging with low-dose CT and CCTA in the Jeroen Bosch Hospital. These individuals served as a control group and were selected via a digital query that only showed the electronic charts of individuals matching for age and gender who had undergone ${ }^{82} \mathrm{Rb}$-PET imaging in the last 2 years and in whom the scan was classified as normal (CFR $>2.0$ and visual normal distribution of the tracer). Subsequently, the indications for ${ }^{82} \mathrm{Rb}$ PET imaging were evaluated. If imaging was used to rule out the presence of CAD in individuals with atypical complaints, the charts of these individuals were evaluated and ESC SCORE risk was calculated. From these, nine charts were randomly selected and included in the control group. The matched individuals underwent a direct venipuncture for the collection of the blood samples in order to assess endothelin-1.

\section{${ }^{82}$ Rb-PET imaging}

All subjects were refrained from caffeine (at least $12 \mathrm{~h}$ prior to PET-imaging) and medication (theophylline, dipyridamole, asasantin, cafergot and/or ergotamine) was discontinued at least $48 \mathrm{~h}$ prior to PET imaging. The subjects were positioned in a 3-dimensional PET system (Siemens Biograph mCT 64 CT slices CT) and a low-dose CT scan was acquired for attenuation correction with an effective radiation dose of approximately $0.2-0.3 \mathrm{mSv}$. Subsequently, pharmacological stress was induced via administration of 
$140 \mathrm{mcg} / \mathrm{kg} / \mathrm{min}$ adenosine for a 6 -minute infusion duration. Three minutes after the start of infusion of adenosine, $1100 \mathrm{MBq}$ of ${ }^{82} \mathrm{Rb}$-Chloride was injected. Dynamic stress images were obtained during a 7-minute acquisition after the ${ }^{82} \mathrm{Rb}$ injection. After acquisition, the ${ }^{82} \mathrm{Rb}$-generator needed $10 \mathrm{~min}$ for regeneration and subsequently another $1,100 \mathrm{MBq}{ }^{82} \mathrm{Rb}$ Chloride was injected and rest images were obtained during $7 \mathrm{~min}$ of acquisition.

\section{CCTA}

After PET imaging, subjects underwent CCTA (Siemens Flash dual source 128 slice). Prior to the ${ }^{82} \mathrm{Rb}$-PET scan and CCTA, a coronary artery calcium score (CACS) was measured. In case of a CACS 600 Agatston Units (AU), CCTA was cancelled as the diagnostic value of CCTA is markedly limited above this score. The effective radiation dose of CACS and CCTA was $2.5-3 \mathrm{mSv}$.

\section{Statistical analysis}

All data were analysed using SPSS 22 statistical software (SPSS Inc, Chicago IL, USA). Differences in continuous data between both study groups were evaluated by the unpaired Student's t-test and categorical data by the chi-squared test. For all statistical comparisons, the level of significance was set at $p<0.05$.

\section{Results}

\section{Patient characteristics}

In total, 9 asymptomatic male athletes with abnormal ET and MPS results and no obstructive CAD and 9 matched control subjects with a normal ${ }^{82} \mathrm{Rb}-\mathrm{PET}$ scan and CCTA and low-to-intermediate risk of CAD were included for analysis. Tab. 1 shows the characteristics of the athletes and the matched controls. The mean age of the athletes was $53.3 \pm 11$.3 years versus $52.7 \pm 11.9$ years $(p=0.905)$ in the control group. All subjects had a low ESC SCORE risk $(2.6 \pm 1.9 \%$ versus $2.4 \pm 2.2 \%, p=0.909$ respectively) and showed comparable total cholesterol levels $(4.8 \pm 0.4 \mathrm{mmol} / \mathrm{l}$ versus $4.8 \pm 0.6 \mathrm{mmol} / 1, \quad p=0.962)$. Resting systolic and diastolic blood pressure measurements were also comparable between both groups. Athletes achieved a mean maximal systolic blood pressure of $195.5 \pm 21.9 \mathrm{~mm} \mathrm{Hg}$ and mean maximal diastolic blood pressure of $77.8 \pm 9.4 \mathrm{mmHg}$. None of the athletes showed a hypertensive response to exercise. Resting ECG showed sinus rhythm in all subjects. Six athletes (67\%) and 2 controls (22\%) met ECG criteria (Sokolow) for left ventricular hypertrophy $(p=0.028)$, whereas incomplete right bundle branch block was found in 2 athletes $(22 \%)$ and 4 controls $(44 \%)(p=0.470)$. $\mathrm{T}$-wave inversion beyond V2 was present in 1 athlete $(11 \%)$ and 1 control $(11 \%)(p=1.000)$ and both subjects also showed incomplete right bundle branch
Table 1 Comparison of the matched characteristics between athletes with concordant abnormal ET and MPS results and the matched individuals with low-to-intermediate risk of CAD

\begin{tabular}{|c|c|c|}
\hline & Athletes $(n=9)$ & Controls $(n=9)$ \\
\hline Age, years $\pm S D$ & $53.3 \pm 11.3$ & $52.7 \pm 11.9$ \\
\hline Gender, M (\%) & $9(100)$ & $9(100)$ \\
\hline ESC SCORE RISK, mean (\%) & $2.6 \pm 1.9$ & $2.4 \pm 2.2$ \\
\hline Total cholesterol, $\mathrm{mmol} / \mathrm{l} \pm \mathrm{SD}$ & $4.8 \pm 0.4$ & $4.8 \pm 0.6$ \\
\hline \multicolumn{3}{|l|}{ Resting blood pressure $(\mathrm{mm} \mathrm{Hg})$} \\
\hline Systolic, mean \pm SD & $131.4 \pm 19.6$ & $123.4 \pm 8.7$ \\
\hline Diastolic, mean \pm SD & $66.8 \pm 7.0$ & $73.9 \pm 11.0$ \\
\hline \multicolumn{3}{|l|}{ Maximal blood pressure $(\mathrm{mm} \mathrm{Hg})$} \\
\hline Systolic, mean $\pm S D$ & $195.6 \pm 21.9$ & \\
\hline Diastolic, mean \pm SD & $77.8 \pm 9.4$ & \\
\hline Rate-pressure product & $9551.3 \pm 1738.6$ & $8723.6 \pm 1457.5$ \\
\hline Training hours/week & $8 \pm 2.7$ & n.a. \\
\hline \multicolumn{3}{|l|}{ Type of Sport } \\
\hline $\mathrm{HS} / \mathrm{HD}, n(\%)$ & $8(88.9)$ & n.a. \\
\hline LS/HD, $n(\%)$ & $1(11.1)$ & n.a. \\
\hline \multicolumn{3}{|l|}{ Resting ECG } \\
\hline Sinus rhythm, $n$ (\%) & $9(100)$ & $9(100)$ \\
\hline LVH & $6(66.7)$ & $2(22.2)$ \\
\hline icRBBB & $2(22.2)$ & $4(44.4)$ \\
\hline TWI & $1(11.1)$ & $1(11.1)$ \\
\hline \multicolumn{3}{|l|}{ Echocardiographic parameters } \\
\hline LVEDD, mean \pm SD $(\mathrm{mm})$ & $48.7 \pm 4.1$ & n.a. \\
\hline IVSd, mean \pm SD (mm) & $9.8 \pm 1.8$ & n.a. \\
\hline PWTd, mean \pm SD (mm) & $9.4 \pm 0.8$ & n.a. \\
\hline LV mass, mean $\pm \mathrm{SD}(\mathrm{g})$ & $164.4 \pm 29.1$ & n.a. \\
\hline $\begin{array}{l}\text { LV mass index, mean } \pm \text { SD } \\
\text { (g.m-2) }\end{array}$ & $80.6 \pm 14.7$ & n.a. \\
\hline $\begin{array}{l}\text { MPS ischaemic defects, } \\
\text { mean } \pm \text { SD }\end{array}$ & $2.4 \pm 0.7$ & n.a. \\
\hline \multicolumn{3}{|l|}{ Location ischaemic defects, $N$ (\%) } \\
\hline Anterior & $4(44.4)$ & n.a. \\
\hline Anteroseptal & $1(11.1)$ & n.a. \\
\hline Inferolateral & $1(11.1)$ & n.a. \\
\hline Lateral & $2(22.2)$ & n.a. \\
\hline Basal lateral & $1(11.1)$ & n.a. \\
\hline \multicolumn{2}{|c|}{ Location ischaemic defects on PET, $N q(\%)$} & \multirow[t]{4}{*}{ n.a. } \\
\hline Matched & $4(45)$ & \\
\hline Mismatched & $2(22)$ & \\
\hline No ischaemic defect & $3(33)$ & \\
\hline \multicolumn{3}{|l|}{ Primary diagnostic evaluation } \\
\hline CAG, normal & $8(88.9)$ & n.a. \\
\hline CCTA, normal & $1(11.1)$ & n.a. \\
\hline \multicolumn{3}{|c|}{$\begin{array}{l}E T \text { exercise test, MPS myocardial perfusion scintigraphy, CAD coronary } \\
\text { artery disease, SD standard deviation, ESC European Society of Cardiol- } \\
\text { ogy, HS high-static, HD high-dynamic, LS low-static, LVH left ventricular } \\
\text { hypertrophy, icRBBB incomplete right bundle branch block, TWIT-wave in- } \\
\text { version, LVEDD left ventricular end-diastolic diameter, IVSd interventricular } \\
\text { septal wall thickness at diastole, PWTd posterior wall thickness at diastole, } \\
\text { LVleft ventricular, MPS myocardial perfusion scintigraphy, CCTA computed } \\
\text { tomography coronary angiography, CAG coronary angiography, n.a. not } \\
\text { applicable }\end{array}$} \\
\hline
\end{tabular}


Table 2 Comparison of the ${ }^{82} \mathrm{Rb}-\mathrm{PET}$ imaging and CCTA results between athletes with concordant abnormal ET and MPS results and the matched individuals with low-tointermediate risk of CAD

\begin{tabular}{|c|c|c|c|}
\hline & Athletes $(N=9)$ & Control $(N=9)$ & $p$-value \\
\hline \multicolumn{4}{|c|}{ Resting coronary blood flow ( $\mathrm{ml} / \mathrm{g} / \mathrm{min})$} \\
\hline LAD & $1.1 \pm 0.4$ & $0.8 \pm 0.2$ & 0.052 \\
\hline $\mathrm{RCx}$ & $1.0 \pm 0.3$ & $0.8 \pm 0.2$ & 0.143 \\
\hline RCA & $0.9 \pm 0.3$ & $0.7 \pm 0.2$ & 0.104 \\
\hline Global & $1.1 \pm 0.3$ & $0.8 \pm 0.2$ & 0.068 \\
\hline Corrected global flow & $1.0 \pm 0.2$ & $0.9 \pm 0.1$ & 0.218 \\
\hline \multicolumn{4}{|c|}{ Maximum coronary blood flow ( $\mathrm{ml} / \mathrm{g} / \mathrm{min})$} \\
\hline LAD & $3.5 \pm 0.8$ & $3.2 \pm 0.6$ & 0.349 \\
\hline $\mathrm{RCx}$ & $3.0 \pm 0.6$ & $3.2 \pm 0.4$ & 0.262 \\
\hline RCA & $3.1 \pm 0.8$ & $3.2 \pm 0.5$ & 0.741 \\
\hline Global & $3.2 \pm 0.7$ & $3.2 \pm 0.5$ & 0.841 \\
\hline \multicolumn{4}{|c|}{ Coronary flow reserve (ml/g/min) } \\
\hline LAD & $3.3 \pm 0.9$ & $4.1 \pm 0.7$ & 0.080 \\
\hline $\mathrm{RCx}$ & $3.1 \pm 0.7$ & $4.1 \pm 0.5$ & 0.003 \\
\hline RCA & $3.4 \pm 0.8$ & $4.5 \pm 0.6$ & 0.004 \\
\hline Global & $3.3 \pm 0.8$ & $4.2 \pm 0.6$ & 0.014 \\
\hline Corrected CFR & $3.2 \pm 0.6$ & $3.9 \pm 0.6$ & 0.045 \\
\hline CACS & $61.1 \pm 157.5$ & $33.3 \pm 50.0$ & 0.621 \\
\hline \multicolumn{4}{|l|}{ CCTA } \\
\hline $\begin{array}{l}\text { No epicardial CAD, } N \\
(\%)\end{array}$ & $9(100)$ & $9(100)$ & 1.000 \\
\hline \multicolumn{4}{|c|}{$\begin{array}{l}P E T \text { positron emission tomography, } E T \text { exercise test, } M P \text { myocardial perfu- } \\
\text { sion scintigraphy, } C A D \text { coronary artery disease, } L A D \text { left anterior descending } \\
\text { artery, } R C X \text { circumflex artery, RCA right coronary artery, CFR coronary flow } \\
\text { reserve, CACS coronary artery calcium score, CCTA coronary computed } \\
\text { tomography angiography }\end{array}$} \\
\hline
\end{tabular}

block. Echocardiography was performed in 8 athletes and the mean left ventricular mass was $164.4 \pm 29.1 \mathrm{~g}$ and left ventricular mass index $80.6 \pm 14.7 \mathrm{~g} / \mathrm{m}^{2}$. There was an inverse correlation between left ventricular mass index and CFR $(r=-0.621)$.

Athletes practised predominantly high-static/highdynamic sports $(90 \%)$ categorised according to the Mitchell classification of sports for an average of $8.0 \pm 2.7$ training hours per week [11]. Using a 17-segment model of the left ventricle, an average of $2.4 \pm 0.7$ segments with reversible myocardial ischaemia were seen on MPS. The locations of these segments were anterior $(44 \%)$, lateral $(22 \%)$, anteroseptal (11\%), inferolateral (11\%) and basal lateral (11\%). Resting and stress PET images were visually compared by the nuclear physician with the obtained perfusion images during MPS. PET imaging matched these ischaemic segments in 4 athletes (45\%), there was a mismatch in 2 athletes $(22 \%)$ and no ischaemic defects were seen in 3 athletes (33\%). During primary diagnostic evaluation after abnormal MPS, 8 athletes underwent coronary angiography and 1 athlete underwent CCTA which showed no obstructive CAD in all athletes.
Table 3 Comparison of the laboratory results between athletes with concordant abnormal ET and MPS results and the matched individuals with low-to-intermediate risk of $C A D$

\begin{tabular}{|c|c|c|c|}
\hline & $\begin{array}{l}\text { Athletes } \\
(N=9)\end{array}$ & $\begin{array}{l}\text { Controls } \\
(N=9)\end{array}$ & $p$-value \\
\hline $\mathrm{CRP}(\mathrm{mg} / \mathrm{l} \pm \mathrm{SD})$ & $0.9 \pm 0.7$ & $0.8 \pm 0.6$ & 0.624 \\
\hline $\begin{array}{l}\text { Leukocyte count } \\
\left(x 10^{\wedge} 9 / / \pm S D\right)\end{array}$ & $5.5 \pm 1.3$ & $7 \pm 0.7$ & 0.013 \\
\hline $\begin{array}{l}\text { Creatinine clearance } \\
(\mathrm{ml} / \mathrm{min} / 1.7 \pm \mathrm{SD})\end{array}$ & $57.1 \pm 4.9$ & $>60 \pm 0.0$ & 0.116 \\
\hline Glucose $(\mathrm{mmol} / \mathrm{l} \pm \mathrm{SD})$ & $5.5 \pm 0.8$ & $5.5 \pm 0.5$ & 0.859 \\
\hline Total cholesterol $(\mathrm{mmol} / \mathrm{I} \pm \mathrm{SD})$ & $4.8 \pm 0.4$ & $4.8 \pm 0.6$ & 0.962 \\
\hline Triglyceride $(\mathrm{mmol} / \mathrm{I} \pm \mathrm{SD})$ & $1.1 \pm 0.4$ & $2.0 \pm 1.4$ & 0.103 \\
\hline $\mathrm{HDL}(\mathrm{mmol} / \mathrm{I} \pm \mathrm{SD})$ & $1.6 \pm 0.4$ & $1.4 \pm 0.4$ & 0.423 \\
\hline Chol/HDL ratio & $3.2 \pm 0.7$ & $3.7 \pm 1.3$ & 0.383 \\
\hline $\mathrm{LDL}(\mathrm{mmol} / \mathrm{I} \pm \mathrm{SD})$ & $2.8 \pm 0.4$ & $2.5 \pm 0.4$ & 0.192 \\
\hline $\mathrm{ET}-1(\mathrm{pg} / \mathrm{ml} \pm \mathrm{SD})$ & $1.3 \pm 0.2$ & $1.0 \pm 0.2$ & 0.012 \\
\hline
\end{tabular}

$E T$ exercise test, MPS myocardial perfusion scintigraphy, $C A D$ coronary artery disease, $S D$ standard deviation, $C R P C$-reactive protein, $H D L$ high-density lipoprotein cholesterol, LDL low-density lipoprotein cholesterol, $E T-1$ endothelin-1

\section{Coronary blood flow measurements and coronary artery calcium scores}

As presented in Tab. 2, low coronary artery calcium scores were observed in both groups $(61.1 \pm 157.5 \mathrm{AU}$ versus $33.3 \pm 50.0 \mathrm{AU}, p=0.621$ respectively). Also, none of the included subjects showed obstructive CAD on CCTA. Resting and maximal myocardial blood flow were assessed via ${ }^{82} \mathrm{Rb}$-PET imaging in all three coronary artery territories. Global myocardial blood flow was calculated and corrected for rate pressure product. No significant differences were observed for (corrected) resting and maximal myocardial blood flow measurements between athletes and matched controls. However, CFR showed a significant lower mean global CFR in athletes $(3.3 \pm 0.8$ versus $4.2 \pm 0.6$ in controls, $p=0.014$ respectively), even when corrected for rate pressure product $(3.2 \pm 0.6$ versus $3.9 \pm 0.6$ in controls, $p=0.045$ respectively).

\section{Biochemical measurements}

Endothelin-1 concentrations were significantly higher in athletes $(1.3 \pm 0.2 \mathrm{pg} / \mathrm{ml}$ versus $1.0 \pm 0.2 \mathrm{pg} / \mathrm{ml}$, $p=0.012$ respectively) as shown in Tab. 3 . There was no correlation between endothelin-1 concentrations and mean global CFR $(r=0.12)$. Total leucocyte count was significantly lower in athletes $\left(5.5 \pm 1.3 \times 10^{\wedge} 9 / 1\right.$ versus $7.0 \pm 0.7 \times 10^{\wedge} 9 / 1, \quad p=0.013$ respectively). No significant differences were found in the levels of C-reactive protein, creatinine clearance, glucose and lipid spectrum between groups. 


\section{Discussion}

The results of this study demonstrate that athletes with abnormal ET and MPS outcomes indicative for myocardial ischaemia without obstructive CAD have a lower CFR when compared with non-athletes with low-to-intermediate a priori risk of CAD, suggesting an attenuated coronary microvascular function. Higher endothelin-1 concentrations in athletes support the hypothesis that endothelial-dependent dysfunction is an important determinant of coronary microvascular function in these subjects.

CFR can be reduced by either stenoses of the epicardial coronary arteries, coronary microvascular dysfunction or a combination of both. As obstructive CAD was ruled out, the impaired CFR in the athletes included in the present study is likely to reflect coronary microvascular dysfunction. Although the global CFR exceeded the cut-off value of $\mathrm{CFR}<2.0$, which is associated with worse cardiovascular outcome [12], the CFR in these subjects was substantially lower when compared with other studies that investigated the CFR in athletes $(3.3 \pm 0.8$ versus $5.9 \pm 1.0$ and $6.1 \pm 1.9$ respectively) $[13,14]$. Even in non-athletes, the CFR values were higher when compared with CFR values of the athletes in the present study $(3.8 \pm 0.7$ and $3.7 \pm 0.7$ versus $3.3 \pm 0.8$ respectively) $[13,14]$. Although the previous studies used different modalities for measuring CFR (such as echocardiography and oxygen-15 labelled water $\left[15 \mathrm{O}-\mathrm{H}_{2} \mathrm{O}\right]$ ), in literature ${ }^{82} \mathrm{Rb}-\mathrm{PET}$ imaging has been validated by comparison with $\mathrm{N} 13$-ammonia and $15 \mathrm{O}-\mathrm{H}_{2} \mathrm{O}$ tracers with a high accuracy of myocardial blood flow estimates in the clinically relevant range. Therefore, the results of our study suggest an attenuated coronary microvascular function in athletes with abnormal ET and MPS results in the absence of obstructive CAD.

An attenuated coronary microvascular function in the absence of obstructive CAD reflects either functional or structural abnormalities of the small coronary arterioles as they are the major determinants of resistance in the coronary vasculature. A functional derangement that may cause a reduction in CFR is endothelial dysfunction [15]. An imbalance between the endothelial-derived vasodilator (nitric oxide) and vasoconstrictor (endothelin-1) is proposed to be the disrupted regulatory mechanism. During oxidative stress, such as exercise, there is overexpression of endothelin-1 which leads to an enhanced vasoconstrictive state together with an impaired vasodilation through a reduced secretion of nitric oxide. In the present study, endothelin-1 concentrations of the athletes were significantly higher when compared with matched individuals with a low-to-moderate a priori risk, suggesting an attenuated expression of endothelin-1 in athletes. These results therefore suggest that endothelial-dependent dysfunction may be an important determinant of the attenuated coronary microvascular function in athletes with concordant abnormal ET and MPS results in the absence of obstructive CAD. This suggestion is strengthened by the observation that the expected sports-related increase in hyperaemic myocardial blood flow was not seen in this group of athletes. This indicates that there is a diminished vascular smooth muscle cell relaxation of the coronary arterioles due to the abovementioned imbalance. Yet, besides functional derangements, structural abnormalities of the coronary microcirculation should also be considered.

Left ventricular pressure overload during exercise was shown to induce medial wall thickening of the arterioles with up to a twofold increase of the wall/ lumen ratio [16], resulting in insufficient myocardial blood flow at rest. As animal studies showed that exercise-induced remodelling of the intramyocardial arterioles was highly age-dependent [7], this may have played a role in the present study targeting middle-aged athletes. Although no left ventricular hypertrophy was documented on echocardiography, data showed a significant inverse correlation between left ventricular mass index and CFR, supporting the theory that there was insufficient remodelling of the coronary microvasculature.

\section{Limitations}

Before drawing conclusions, we need to address several limitations. First, the ${ }^{82} \mathrm{Rb}-\mathrm{PET}$ imaging results in athletes were compared with a non-athletic population with a low-to-moderate a priori risk who already underwent ${ }^{82} \mathrm{Rb}$-PET imaging, which could have led to a selection bias. Second, the study consisted solely of middle-aged male athletes with a low risk of CAD. Therefore, the results of this study cannot be generalised to athletes with a moderate or high a priori risk and women in whom an attenuated microvascular function could be more pronounced. Third, only athletes with segmental myocardial ischaemia on MPS were selected as coronary microvascular dysfunction could be distributed heterogeneously in the myocardium [17]. However, other studies showed that coronary microvascular dysfunction could also be distributed homogeneously throughout the walls of the left ventricle and is most frequently not associated with reversible perfusion defects seen on MPS [18]. Therefore, the results of the present study cannot be generalised for athletes with homogeneous coronary microvascular dysfunction and the prevalence of coronary microvascular dysfunction in athletes could be even higher than previously documented. Finally, as this study comprises only 9 athletes, studies in larger populations are needed to draw definitive conclusions.

\section{Conclusion}

Athletes with abnormal ET and MPS results indicative for myocardial ischaemia and without obstruc- 
tive CAD showed a lower CFR when compared with non-athletes with a low-to-intermediate a priori risk of CAD, suggesting an attenuated coronary microvascular function. Higher endothelin-1 concentrations in athletes suggest that endothelial-dependent dysfunction may be an important determinant of the attenuated coronary microvascular function. Since this finding may have important clinical implications, future studies should be conducted with a long follow-up period to investigate whether or not preventive strategies should be considered.

Acknowledgements The authors wish to thank the participants, the Department of Sports Medicine and the echocardiography division of the Department of Cardiology.

Funding The author(s) received no financial support for the research, authorship and/or publication of this article.

Conflict of interest D.A.J.P. van de Sande, P.C. Barneveld, J. Hoogsteen, P.A. Doevendans and H.M.C. Kemps declare that they have no competing interests.

Ethical standards All procedures performed in studies involving human participants or on human tissue were in accordance with the ethical standards of the institutional and/or national research committee and with the 1975 Helsinki declaration and its later amendments or comparable ethical standards. Informed consent was obtained from all individual participants included in the study.

Open Access This article is distributed under the terms of the Creative Commons Attribution 4.0 International License (http://creativecommons.org/licenses/by/4.0/), which permits unrestricted use, distribution, and reproduction in any medium, provided you give appropriate credit to the original author(s) and the source, provide a link to the Creative Commons license, and indicate if changes were made.

\section{References}

1. Maron BJ, Araújo CG, Thompson PD, et al. Recommendations for preparticipation screening and the assessment of cardiovascular disease in masters athletes: an advisory for healthcare professionals from the working groups of the World Heart Federation, the International Federation of Sports Medicin. Circulation. 2001;103:327-34.

2. Borjesson M, Urhausen A, Kouidi E, et al. Cardiovascular evaluation of middle-aged/senior individuals engaged in leisure-time sport activities: position stand from the sections of exercise physiology and sports cardiology of the
EuropeanAssociation ofCardiovascularPrevention and Rehabilitation. Eur JCardiovasc Prev Rehabil. 2011;18:446-58.

3. Pigozzi F. Role of exercise stress test in master athletes. Br J Sports Med. 2005;39:527-31.

4. van de Sande DA, Breuer MA, Kemps HM. Utility of exercise electrocardiography in pre-participation screening in asymptomatic athletes: a systematic review. Sport Med. 2016;46:1155-64.

5. van deSande DA, Liem IH, Hoogsteen J, et al. The diagnostic accuracy of myocardial perfusion scintigraphy in athletes with abnormal exercise test results. Eur J Prev Cardiol. 2017;24:1000-7.

6. HendelR, AbbottB, Bateman T, etal. Theroleofradionuclide myocardial perfusion imaging for asymptomatic individuals. J Nucl Cardiol. 2011;18:3-15.

7. Duncker D, Bache R. Regulation of coronary blood flow during exercise. Physiol Rev. 2008;88:1009-86.

8. Crea F, Camici PG, Bairey Merz CN. Coronary microvascular dysfunction: an update. Eur Heart J. 2014;35:1101-11.

9. van Middelkoop M, van Linschoten R, Berger MY, et al. Knee complaints seen in general practice: active sport participants versus non-sport participants. BMC Musculoskelet Disord. 2008;9:36.

10. Piepoli MF, Hoes AW, Agewall S, et al. European guidelines on cardiovascular disease prevention in clinical practice. Eur HeartJ. 2016;37:2315-81.

11. Mitchell JH, Haskell W, Snell P, et al. Task force 8: classification of sports. JAm Coll Cardiol. 2005;45:1364-7.

12. Nakanishi K, Fukuda S, Shimada K, et al. Prognostic value of coronary flow reserve on long-term cardiovascular outcomes in patients with chronic kidney disease. Am J Cardiol. 2013;112:928-32.

13. Hildick-Smith DJ. Coronary flow reserve is supranormal in endurance athletes: an adenosine transthoracic echocardiographic study. Heart. 2000;84:383-9.

14. Toraa M, PouillardF, MerletP, etal. Cardiachypertrophy and coronary reserve in endurance athletes. Can J Appl Physiol. 1999;24:87-95.

15. MonteroD, WaltherG, Diaz-CañestroC, etal. Microvascular dilator function in athletes: a systematic review and metaanalysis. Med Sci Sports Exerc. 2015;47:1485-94.

16. Folkow B, Hallback M, Noresson E. Vascular resistance and reactivity of the microcirculation in hypertension. Blood Vessels. 1978;15:33-45.

17. Marroquin O, Holubkov R, Edmundowicz D, et al. Heterogeneity of microvascular dysfunction in women with chest pain not attributable to coronary artery disease: implications for clinical practice. Am Heart J. 2003;145:628-35.

18. Kibel A, Selthofer-Relatic K, Drenjancevic I, et al. Coronary microvascular dysfunction in diabetes mellitus. J Int Med Res. 2017;45:1901-29. 


\title{
Advertisement placed here.
}

\author{
ces bohn \\ CL van loghum
}

Houten 2019 


\title{
Advertisement placed here.
}

\author{
ces bohn \\ CL van loghum
}

Houten 2019 